\title{
Preoperation anxiety: a qualitative analysis
}

\author{
P. O. BODLEY, H. V. R. JONES, AND M. D. MATHER \\ From the Department of Anaesthesia, Oldchurch Hospital, Romford, Essex, \\ the Adolescent Psychiatric Unit, Whitchurch Hospital, Cardiff, and the \\ Department of Clinical Psychology, Warley Hospital, Brentwood, Essex
}

SYNOPSIS Twenty-eight patients were investigated psychologically before surgery. The purposes of the study were (1) to discover the nature of preoperative anxiety, and (2) to compare direct questioning with an indirect method. The merits and shortcomings of the two types of assessment emerged. The findings suggest that, in addition to worries about the operation and the anaesthetic, there was concern about leaving the home and family, which was accentuated by lack of communication and contact with hospital staff, including the surgical team. Pain was found to have a variety of implications including loneliness. These and other findings are discussed in relation to psychological theories.

Most patients suffer from an unpleasant state of mind (uneasiness, anxiety, fear) before an operation. The cause is not clear, nor are the methods for its investigation established. The nature and quality of these feelings depend on the patient's personality and on how he construes and reacts to the preoperative situation. It is also determined by past experiences, whether his own or other people's.

A patient's ability to express feelings and anxieties depends on his verbal fluency, his defence mechanisms regarding emotional experience, the investigator's personality and the interview technique, and social influences varying from the character of the ward and the disposition of other patients to the patient's own cultural environment. A current social attitude to an operation is 'there isn't much to worry about; they can do such marvellous things these days'.

This study is concerned with the problems:

1. What aspects of the situation are significant to the patient and what reactions do they evoke? Do reactions vary from patient to patient or are there some which are common to all, such as a fear of death, of mutilation, or of losing control? (Deutsch, 1965).

2. Does direct questioning produce helpful answers about how and why a patient feels as he does or are some feelings not expressed directlyo and therefore have to be elicited by indirect methods?

To exclude subjective impressions and evaluate only the patient's reactions and attitudes, ao special psychological technique was used (Kelly, 울 1955), the Kelly Grid. It was also hoped theo technique might be of value in answering. problem 2 , as it is non-directive.

\section{METHODS}

KELLY REPERTORY GRID This technique was used to assess the significance and importance of different aspects of the preoperative situation for the patient. It was structured to investigate how a patient perceives and construes the experience.

To administer the test the names of the 'elements' or aspects of the situation are printed on cards which are set out in front of the patient who is required to make judgements on them. If, for instance, elements are people and the 'construct' chosen is 'trustworthy', the patient is asked to select the person most likely to be trustworthy. This card is then extracted and he is asked to select the person most likely to be trustworthy from those that remain, and so on through the cards.

In this way all the 'elements' are ranked or rated on the descriptive constructs. Statistical analysis reveals the most significant 'elements' and the way in which they are construed. Similarly it is also 


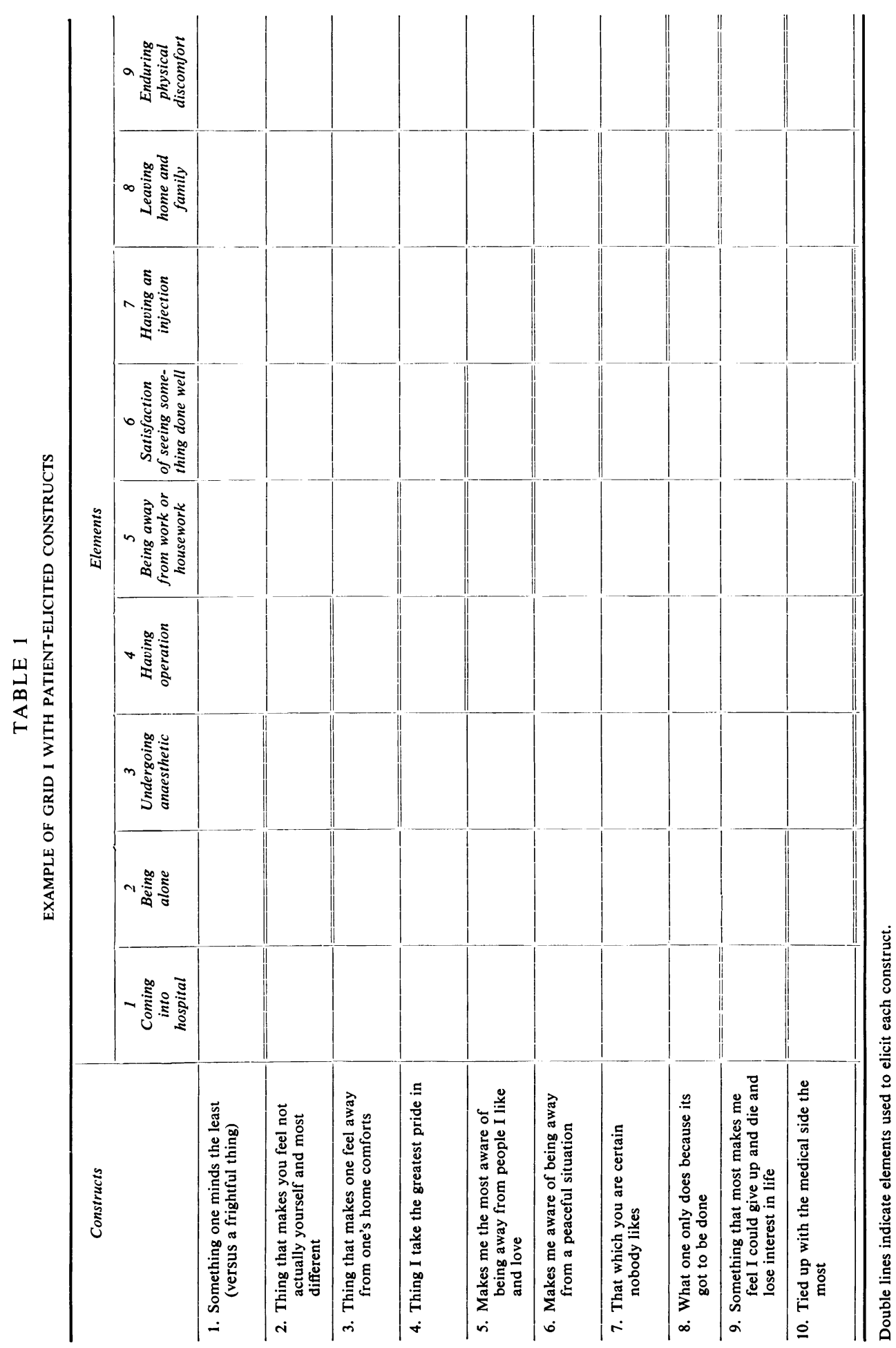




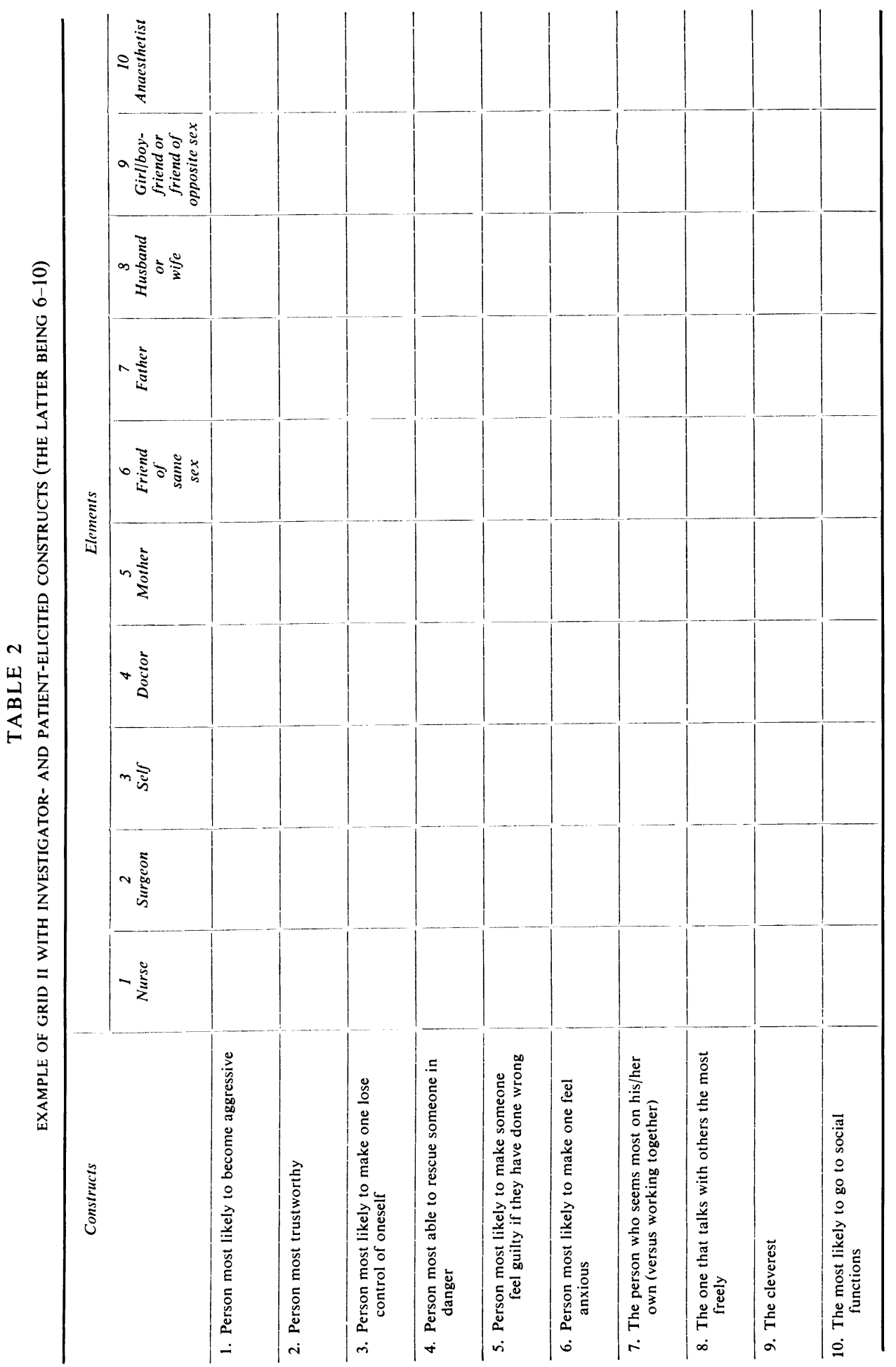

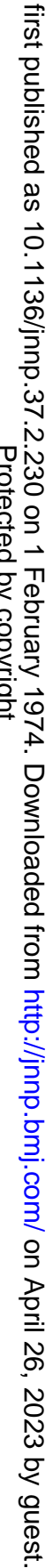


possible to discover those 'elements' which have relatively less meaning and significance.

In this project two grids were used to investigate two areas of experience: first, aspects of the preoperative situation itself (the choice being based on Janis (1958)) - for example, injections and anaesthesia-and, secondly, the people in the situation.

The first grid (Table 1) contained aspects of the preoperative situation as elements. The second grid (Table 2) comprised people as elements (the hospital team, and family members and friends). Some of the descriptive constructs were supplied by the investigators while others were elicited from the patient.

QUESTIONNAIRE This consisted of questioning about anxieties and problems related to the operation and the anaesthetic and was aimed at eliciting anxieties by a direct method (Table 3). The questions were based on a pilot study of 50 patients.

RATIONALE It was hypothesized that a questionnaire would answer problem 1 and the Kelly Grid would answer problem 2 .

\section{TABLE 3}

THE QUESTIONNAIRE

1. Can you say something of what your feelings are about undergoing the operation?

2. Have you any particular anxiety or problem you would like to mention?

3. What do you dislike most in being in hospital for this operation?

4. If so, do you think anything more could be done to lessen this trouble for you?

5. Do you know what the operation is for? Have you been told?

6. How long have you had the symptoms and when did you see a doctor about them?

7. Has there been any delay on the part of the doctors in booking the operation for you?

8. What operations have you had in the past and what was your experience of them?

9. Have there been any difficulties in the home or at work recently which have added to any strain you have had with your illness?

Twenty-eight patients (male and female) admitted consecutively were studied. They were selected from those about to undergo surgery and general anaesthesia in a large regional hospital. On the day before operation the patient was seen by the anaesthetist (P.O.B.) who administered the questionnaire verbally. This was followed by a visit by one of the other authors who administered the Kelly Grid. The patient was introduced to these procedures by an explanation that the results of the tests would help in understanding how people feel being in a ward awaiting operation. The grids were factor-analysed by computer. A comparison was made between the questionnaire and the major factors emerging on grid I. The factor analysis of grid II revealed interpersonal experiences in the situation.

\section{RESULTS}

ANALYSIS OF GRID I (Aspects of the preoperative situation) In this grid only patientelicited constructs were used. Out of the 28 patients, 21 construed 'undergoing the operation' as significant, while 23 considered having an anaesthetic as important. Mostly it seemed that having the anaesthetic was viewed in the same light as having the operation (13 out of 21 ). Nine of the 23 patients distinguished the anaesthetic from the operation and said it meant something different to them.

There were other significant aspects common to many patients. 'The satisfaction of seeing something done well' was meaningful to 25 of the 28. Ten out of 25 considered it produced feelings very different from the thought of the operation-for example, the antithesis of 'most horrible', 'expecting pain', 'detest', 'give discomfort', 'frightening', 'physical stress', 'most lonely'. The 'satisfaction of seeing something done well' emerged as statistically significant, indicating worry about the outcome of the operation and an anticipatory state of anxiety.

Nineteen patients referred to pain or physical discomfort. This subject was either elicited as a 'construct' or a way of describing an element. Pain meant a number of different things. Eight related it to anaesthesia; seven associated it with 'being alone'; four viewed it positively in that it would help them get better; four saw it as merely an indication that something was wrong with them. Sometimes pain meant leaving home.

'Being alone' (as distinct from its implication of pain) is another aspect of the situation which emerged a number of times, sometimes as a significant element and sometimes as descriptive of attitudes. Five of 16 patients, who considered loneliness was important, felt the operation produced the feelings; four saw it as the result of leaving home; and three related it to pain or physical discomfort.

'Leaving home' had implications for 14 of the 28. Five considered it caused loneliness and 
three related it to pain. The feelings produced by leaving home were described by such 'constructs' as: 'I dread it, I would shift heaven and earth to avoid it'; 'weighs down with worry the most'; 'going into another world'; 'can feel these in your mind'; 'a wrench most frightening'; 'makes me feel I would give up and die'.

These were the most significant 'elements' and 'constructs' to emerge on grid I. It is interesting that half of the patients who were concerned with leaving home were also worried about the operation. Of those concerned with the operation, one-third revealed significant feelings about leaving home. Being away from work was important but was viewed positively and happily.

Eight patients considered the operation meant something different from the anaesthetic. Of these three only expressed fears of death. The constructs used were 'makes one think of dying'; 'concern your life'; 'feeling of having to leave the family and perhaps not waking up'.

The ways in which the operation and anaesthesia were construed similarly were as follows: 'pain and punishment'; 'physical sensation'; 'not being able to do anything'; 'most nervous feeling I can't tell you'; 'in great pain and loneliness'; 'think I am the only one having it happen to me'; 'can be nerve-racking'; 'done for the good it will do'; 'aware of being away from people I like and love'; 'on your own in a world having physical discomfort'. For most people, having the anaesthetic has as much meaning as the operation and may produce the same unpleasant feelings.

RESULTS OF QUESTIONNAIRE AND GRID I Fig. $1 \stackrel{\overrightarrow{\bar{N}}}{\stackrel{\vec{F}}{(1}}$ shows that the grid technique has elicited some important aspects which did not appear on direct questioning. The satisfactory end-resultthat is, something having been done well-was emphasized by the grid to be highly significant to in a majority of patients. The questionnaire $\overrightarrow{0}$ generally did not elicit this. The anaesthetic was as important to 23 patients as the operation itself yet direct questioning produced only three references to this. Pain and its various meanings emerge strikingly on the grid but to a lesser extent on the questionnaire. The feeling of $i$ loneliness was elicited only by the grid and is $\tilde{S}^{-}$ clearly important. Missing home is of conse quence but this may be also discovered by direct questioning.

Other causes of concern which emerge more on the grid than on the questionnaire are feeling

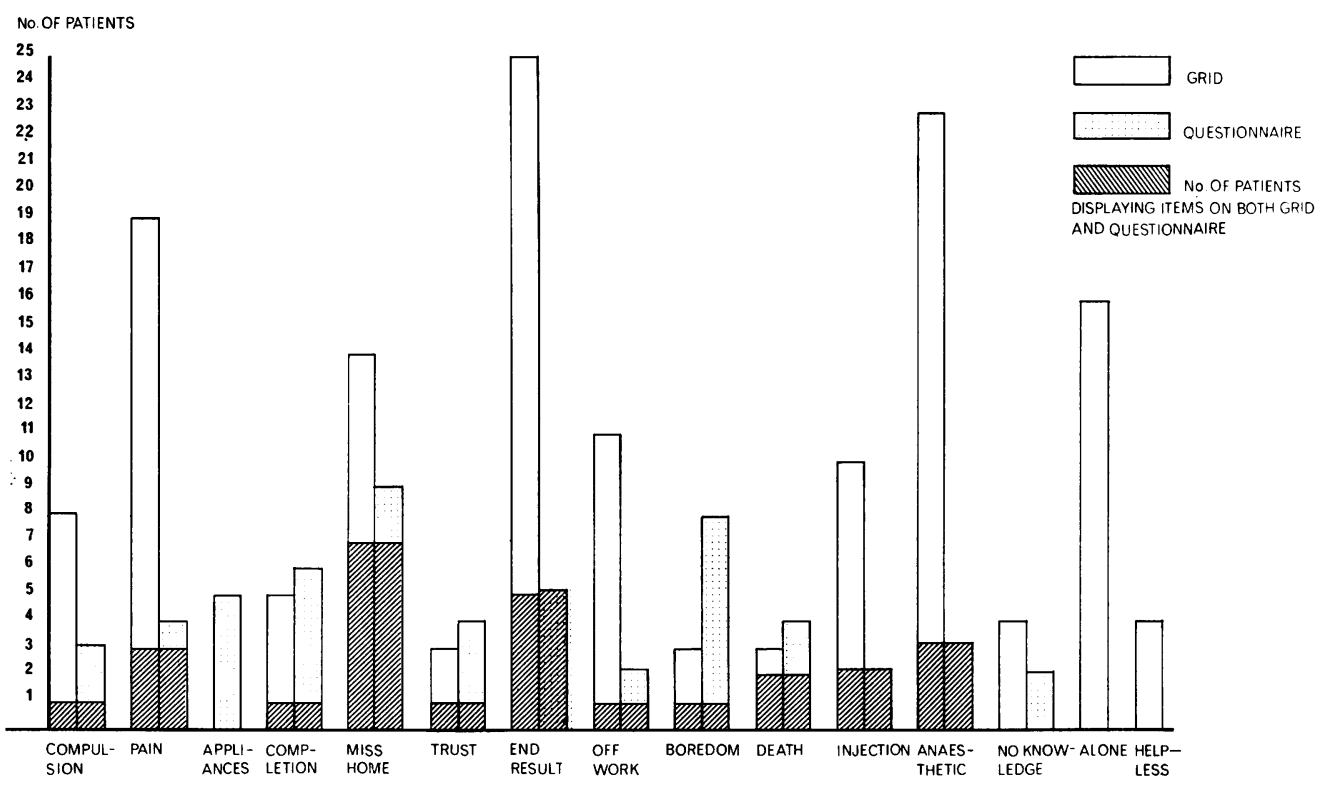

FIG. 1. Importance of constructs on grid in the preoperative situation. 
of helplessness, lacking knowledge, fear of injections, and a feeling of being compelled to go through something unpleasant. These factors are of secondary importance (Fig. 1).

The questionnaire evoked some comments not found on the grid. Boredom or concern because of waiting or 'hanging about' was mentioned by several patients, and worry over the medical appliances, washing arrangements or the administration of enemas, feelings of having to trust other people, and the possibility of dying are mentioned more often. On the questionnaire none of the patients described any family worries. Only one patient expressed worry about work and one patient reported financial worry. Most of the patients admitted that they had been given adequate information about the operation. Only five thought that it was insufficient. The emergence of anxieties on the grid cannot, therefore, be explained entirely in terms of incomplete information.

Patients who perceive pain as significant are not always those who have suffered the longest; among patients who showed anxiety about pain on grid I, the duration of symptoms varied from three weeks to several years.

Delay in admission into hospital was not a cause of anxiety, only three patients reporting delay.

No relationship between previous operations and anxieties emerges on grid I. Worry about loneliness, pain, the operation, leaving home, and the end-result are shown equally by those who had had previous operations and by those who had none. The evidence is thus equivocal as to whether the conditioning effect of experience immunizes the patient against distress or raises his level of anticipatory anxiety. It is also possible that by the time the patient reaches the hospital ward he has adjusted to the fact that he is to have an operation and his anxieties have subsided.

RESULTS OF GRID II The purpose of this grid was to assess the construing of interpersonal relationships (both in the family and with

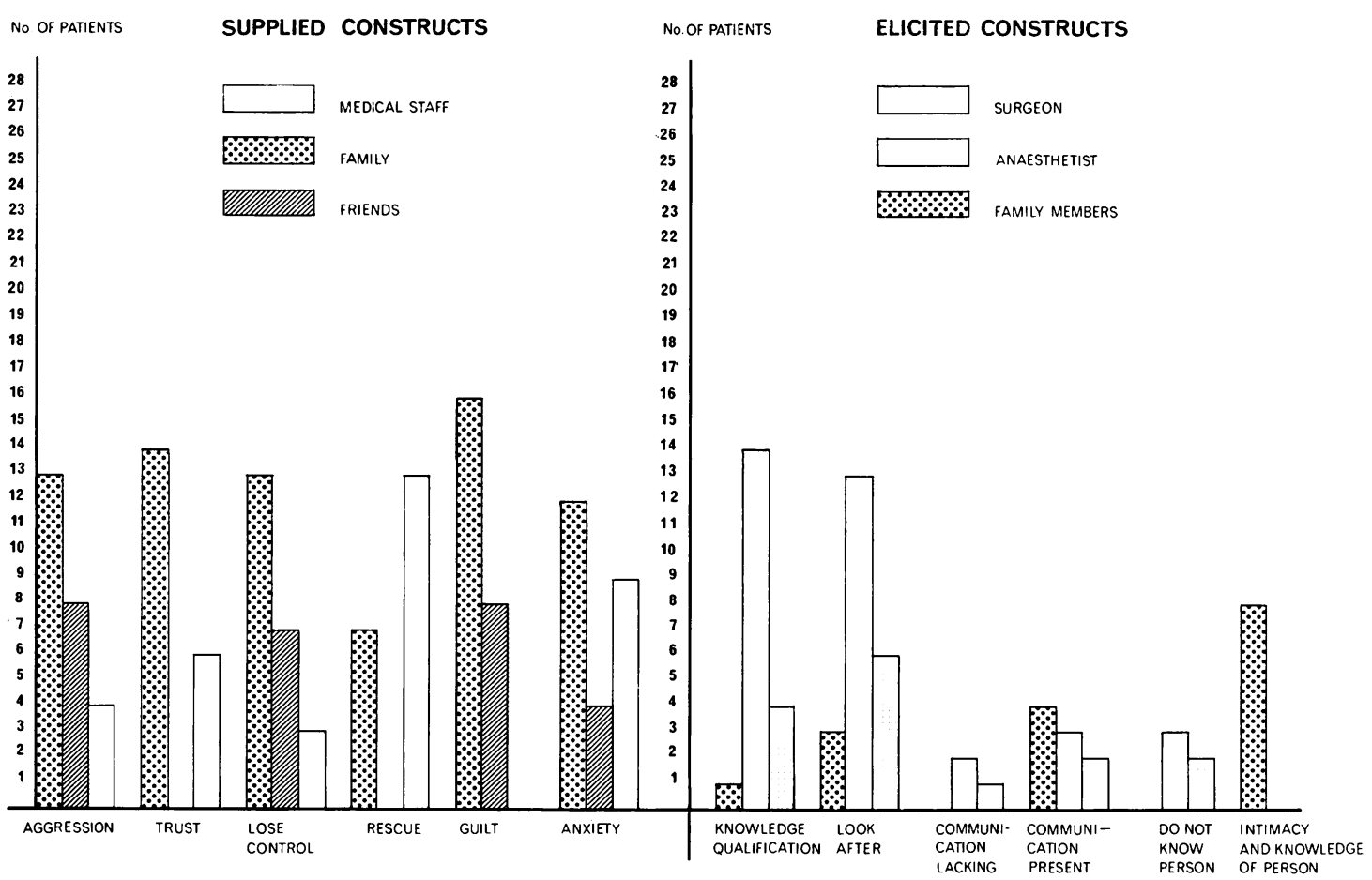

FIG. 2. The results of analysis of grid II. 
hospital staff). As Fig. 2 shows, most of the supplied constructs on grid II-that is, those concerning aggression, trustworthiness, or evoking loss of control, producing guilt and anxiety -are more relevant to members of the family and friends than to the hospital staff. However, the hospital staff were seen as those 'most likely to rescue when in danger' and 'most likely to make one anxious'.

Varying constructs were elicited on this grid and a number of these can be classified under the headings in Fig. 2. In general, the surgeon and anaesthetist are seen as having 'professional knowledge and qualifications' and 'care of the patient', but conveyed no 'intimate and personal knowledge' of themselves to the patient and varied in their level of communication with the patient. Nurses were seen similarly to the medical staff in 24 of 28 cases, so that the nurse was omitted as a separate element for statistical consideration.

Analysis reveals the surgeon as a very significant person to 22 of the 28 patients, and the anaesthetist as significant to 18 of the 28 . Sometimes the anaesthetist was construed in a way similar to the surgeon but 10 patients saw the anaesthetist differently. In only four cases compared with 14 was the anaesthetist seen to have the same knowledge and professional qualifications as the surgeon and, although important, in only six cases was he seen as a person who looks after patients as would a surgeon.

The lack of communication was more a characteristic of the surgeon and anaesthetist than of family members, although some patients did not feel that they knew either of them. The lack of personal knowledge about the surgeon and anaesthetist was of great consequence. Although the anaesthetist is a significant figure he is viewed with less confidence than the surgeon (grid II) and yet, most patients consider that having an anaesthetic is just as important to them as the operation (grid I).

The patients who viewed the anaesthetist differently from the surgeon construed the former negatively. Some of the constructs which emerged for the anaesthetist were "least concerned with your well-being'; 'I do not know and am not related to them'; 'do not give advice'; 'do not help in personal matters'; 'do not understand'. The constructs that were supplied that were most attributed to the anaesthetist included 'do not make one feel guilty'; 'do not make one lose control'; ' are not considered trustworthy'.

While the surgeon is classed with the anaesthetist, he emerges more positively. However, he is not seen as a father figure and in only one case is he construed together with the father.

Before the operation the medical staff do not $\stackrel{\vec{F}}{\vec{g}}$ provoke the same personal feelings as family members, although they tend to become more involved the longer the patient stays in hospital. There is less dependency, aggression, or guilt $\stackrel{\mathbb{D}}{\circ}$ feelings towards the medical staff. The anxiety क which they sometimes evoke is understandable $\vec{\circ}$ but to compensate for this is the fact that they are seen as rescuers in times of trouble.

The lack of involvement with the staff, as seen from grid II, helps to explain the feelings of loneliness and the anxieties about leaving home which emerge on grid I. Even the nurse, who is comes into contact with the patient more ofteg than either the surgeon or anaesthetist, is fres quently classified with the medical staff and everg she does not produce feelings of involvement 迤 the patients.

\section{DISCUSSION}

FEELINGS EVOKED BEFORE OPERATION The feelings experienced by the patient are frequently unpleasant and may evoke an anticipation of danger which serves no useful purpose. These fears are a normal response to a strange and distressing situation from which the patient cannot $\stackrel{\varnothing}{\circ}$ reasonably escape. Although the anxiety may not be manifest in easily recognizable behaviour, it may nonetheless be present (Robertson, 1957; Robertson, 1970). The views of patients are disclosed by the following words: "physical discomfort ... pain, unpleasant to have to endure it ... frightening'; 'thing I mind most ... reminds me of joining up in the war ... upsetting'; 'blooming awful'.

ASPECTS OF SITUATION WHICH PROVOKE PREOPERATIVE ANXIETY Results show that, while some anxieties are shared by many, other anxieties are specific to the individual. Psychoanalytic concepts lead one to look for certain basic themes, especially fears of mutilation and $\mathrm{c}$ 
of death, but of these there is little direct, only some indirect, evidence.

Death The three constructs making direct reference to death are: 'makes me think of dying'; 'something that makes me feel I could give up and die'; and 'feeling of having to leave family and perhaps not waking up'. The reluctance by patients to speak about death may mean that it has replaced sex as a taboo (Gorer, 1965).

Home Separation from home and family has painful overtones and is present in over half the patients. Staff may become so absorbed in the patient's behaviour in the ward that the reaction to being away from home is overlooked. Too little attention is paid to this, despite hints as to its importance such as a display of family photographs. In many instances more could be done to create a home atmosphere. Heightened concern about those left behind may also express a fear of permanent separation (or death) and is reflected in phrases used in the constructs, such as 'that which I would shift heaven and earth to avoid'. This finding is in keeping with Briskin's (1965) study which showed a high percentage of surgical patients were fearful of broken relationships or personal loss by death. Janis (1958) mentions the upsurge of interest in social contacts to establish bonds of affection when a person is in danger of injury or death.

Mutilation Evidence of fear of mutilation is less direct. The emphasis placed on the need for the operation to be performed competently ('the greatest need for it to be done well'; 'know it's being done right') can, in part, be attributed to this.

Anaesthesia and loss of control The fear of anaesthesia may be interpreted occasionally as a fear of losing control-a primitive fear which is sometimes difficult to express-for example, out of control of events or 'doing something silly'. The degree to which anaesthesia is a provocative issue is shown by the fact that it appears as significant on the grids of 18 patients. It is often seen, with its unpleasant connotations, as part of the having-an-operation process.

Pain This featured prominently in the minds of 14 patients (together with the 'death' theme, direct questioning or obvious confrontation in the wording used on the grid was avoided). The results show that patients interpret pain in different ways. Some regard it as a hurtful physical sensation, while others see pain as emotional suffering or concern about the outcome of the operation. During preoperative visits it is important to understand exactly what it is the patient means if he speaks of pain. While an analgesic may help those who are frightened of physical pain, it will do little to console the patient with anxieties. One patient saw pain as a necessary part of being cured; this could reflect an attitude that anything therapeutic must be painful and vice versa. Another patient associated pain with punishment, thus perhaps expiating guilt. Pain can also produce extreme feelings of loneliness-for example 'on your own'; 'in a world having physical discomfort'. Feelings of 'being alone' were often highly distressing, despite the fact that a patient is never physically alone in a hospital ward.

ANXIETIES REVEALED BY DIRECT QUESTIONING AND BY GRID Some anxieties and fears were found on grid I but not uncovered by questioning, others were elicited by both the grid and questioning, while a few were brought to light by questioning but not by the grid (Fig. 1).

It can be seen that pain, loneliness, the anaesthetic, and the outcome of the operation are topics to the forefront of the patient's mind but which he does not talk about on direct questioning. Pain is perhaps too complex in its meanings for him to explain in a short directive interview. Further, it was found, from examining the replies on the duration of illness, that the patients who had suffered longest were not necessarily those who considered pain important.

With regard to anxieties about leaving home, it seemed from the questionnaire that this was not due to family worries that they had left behind.

The lack of knowledge (Fig. 1) is apparently not a reference to inadequate information about the illness. Most of the patients felt, according to the questionnaire, that they had been given sufficient explanation. Probably it refers to a fear of the unknown or uncertainty about the future (Rycroft, 1968).

Boredom A relatively large number of patients (five) spoke of boredom, or of hospital equip- 
ment such as syringes or trolleys. Some people develop a subtle language to express their feelings and, although the replies can be taken at face value, it is possible that they represent fears which are distressing, but not permissible to talk about and may even be unrecognized. For instance, a patient may be prepared to talk about boredom and apparatus but not about his family and the operation.

Boredom may indicate unrelieved tension. Activity as a way of expressing tension is seen in the anxious, restless father-to-be, a role which carries a right to display emotion. Boredom also indicates that time passes slowly during a period of waiting. When there is nothing to do the patient will worry.

Feelings towards staff and family The results separate negative feelings (guilt, anxiety, depression) from positive feelings (reassurance, trust, having knowledge), the former being linked to members of the family or friends and the latter to the hospital staff. Thus, patients divide their expectations and emotions using family members as a target for hostile feelings, which would otherwise be destined for the hospital staff. A patient has a need to see the staff-'the danger control authorities' (Janis, 1958) - as 'good', and in turn presents them with a good picture of himself equating 'good' with 'strong'.

When the surgical team is distant and aloofthat is, lacking in communication and offering no personal acquaintance - the patient's image of them is determined more by his inner needs than objective facts. If the team communicate closely with the patient his feelings will be altered according to the approach adopted. When the staff are comforting and warm, then the patient's feelings of security are increased, for they are living up to his expectations. Conversely, a harsh approach can destroy a necessarily idealistic and protecting image. If members of the surgical team are seen unfavourably this can usually be remedied by a reassuring, even if brief, talk.

There are suggestions of the analytic concept of transference in which the patient develops an emotional attitude, either positive or negative towards the surgeon and others determined by his past experiences of early parental relation- ships and authority. Usually the grid II results show that the surgeon is not seen in the same way as a father, but this is not contradictory if transference is seen as essentially a childhood view of 0 the father and not the adult view. The patient reacts to the surgeon as if he is good, protective and trustworthy and faults are not noticed. According to Janis this is a transference reaction-that is, reminiscent of childlike trust. This positive view of the surgeon is necessary because the patient is in a dependent position and needs to find the 'good' authority-figure. Ideally, this image should be preserved but with greater interpersonal contact. While there is no need for the staff to become too identified with the patient, $\overrightarrow{0}$ the picture of remoteness and aloofness that emerges is not to the good of the patient.

IMPLICATIONS OF PREOPERATIVE VISITING

family There is evidence that before an operation there is a strengthening and occasionally of i renewal of family involvement. Generous oppos tunities for family visiting may confer security i addition to distracting the patient from $h$ anxieties.

(2) By surgical team and hospital staff The tensions and emotions experienced preoper tively render a patient less mature in his persona relationships (Janis, 1958). As well as his becoming more dependent on the family, he becomes emotionally dependent on the hospital staff and needs to talk and discuss freely. There is a discrepancy between how the patient feels $\frac{\partial}{\nabla}$

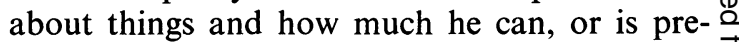
pared, to talk about them. Communication can be improved by the hospital staff showing empathy with the patient. A feeling of 'togetherness' can be engendered by a friendly open approach. The comment 'you'll be all right', while reassuring some, may aggravate others: who see the remark as inappropriate to their 3 own emotional state and make them feel their $\delta$ anxieties are exceptional. The reaction may then $₹$ be a mixture of mistrust, impatience, and with-o drawal and an increased feeling of inadequacy and isolation.

Patients may be helped if staff understand the mechanisms of denial and projection. A sensitive and informed listener appreciates that the mother who says 'I'm not frightened of hospitals, I'm 
worried about my baby, will he settle at night?' is expressing anxieties about her own situation as well as that of the child (projection). Sometimes a patient may express unconcern and the more strongly he proclaims it, the more it may mean he is denying something he cannot face, confess or solve (denial). The following dialogue of mutilation, violence, and catastrophe belies this patient's self-assurance.

A train-driver was asked how he felt. 'Wonderful', he replied, 'I don't feel anything at all about it - no fears-I'm determined to have itnot afraid - got a quiet confidence'. He was then asked if he had any anxieties. 'No, no', he said, 'what comes I'm ready to accept. I've heard about it-you listen to one, listen to another. On my job you see lots of things-people killed and thinking you might have done that. I haven't killed anybody but I've seen people killed. Now if someone was sick over there I couldn't stand it. But my son dug a fork in his instep, he just stood there and pulled the fork out. This gave me no feeling like. My wife would say I'm hard. If she burns herself I'll say-“'You'll know its hot the next time"'. I've got no fear, I'll just take that chance'.

Often the chance remark tells a lot. One patient, having reiterated that she had no worries and said goodbye to the investigator, called after him 'It was nice to have someone to talk to. After all, they don't realize what it's like to have one's body cut up and messed about with'. This comment reveals the intensity of anxiety previously denied by the patient. The patient who complains that 'they never tell you anything' may alternatively mean 'I'm not going to tell you anything' and, in effect, projects his own attitude on to the clinician.

IMPLICATIONS OF STUDY FOR HOSPITAL STAFF Because a successful result to an operation is predicted, it does not mean necessarily that the patient shares the surgical team's optimism. The patient worries about uncertainty, pain (with its various meanings), separation, and loneliness. The presence of these anxieties was not significantly related statistically $(P=0 \cdot 3)$ to duration of illness or to the seriousness of the operation (classified as major, moderate, or minor). These anxieties are individual and subjective-that is, not related to the surgical team's objective assessment of the situation.

Although the shortage of personnel makes it difficult for doctors, nurses, and other professional staff to listen, to reassure, and to explain at the bedside, their role as boosters of morale cannot be overestimated. It is also becoming important, as new management methods are adopted and multibedded district hospitals replace existing local hospitals, that the care and attention given to the psychological needs of the patient are not diminished (Menzies, 1967).

We thank Professor K. Rawnsley of the Welsh National School of Medicine, Cardiff, for his criticism and advice. We acknowledge gratefully the help, in particular with the computer analysis of the grids, given by Dr. Patrick Slater of The Maudsley Hospital, London. We are indebted also to Dr. Phillida Salmon, lately of Bexley Hospital, Dartford, Kent, for her guidance on the grids.

\section{REFERENCES}

Briskin, Pamela (1965). An Investigation into some Psychological Reactions to Surgery. Ph.D. Thesis: London.

Deutsch, H. (1965). Neurosis and Character Types. Hogarth: London.

Gorer, G. (1965). Death, Grief and Mourning in Contemporary Britain. Cresset Press: London.

Janis, I. L. (1958). Psychological Stress, Psychoanalytic and Behavioral Studies of Surgical Patients. Wiley: New York.

Kelly, G. A. (1955). The Psychology of Person Constructs. Norton: New York.

Menzies, I. (1967). The Functioning of Social Systems as a Defence Against Anxiety. Tavistock Publications: London.

Robertson, James (1970). Young Children in Hospital. 2nd edn. Tavistock: London.

Robertson, Joyce (1957). A mother's observations on the tonsillectomy of her four-year-old daughter. Nursing Times, 46, 1295.

Rycroft, C. (1968). Anxiety and Neurosis. Penguin Books. Harmondsworth. 